\title{
The electroencephalographic signature of subacute sclerosing panencephalitis
}

\author{
0 padrão eletrencefalográfico da panencefalite esclerosante subaguda
}

Francisco Pereira da Silva-Júnior' ${ }^{1}$, Mariana Silva Souzaำ, Joaquina Queiroz Andrade', Eliana Garzon²

Periodic long-interval diffuse discharges synchronized with myoclonic jerks in subacute sclerosing panencephalitis (SSPE) are a very specific pattern in electroencephalography ${ }^{1}$. They are characterized by generalized synchronous high-voltage complexes (300-1000 $\mu \mathrm{V})$, composed of two or more waves consisting of variable elements, such as slow waves usually mixed with sharp waves. Complexes last from 0.5 to 3 seconds and recur every 5-7 seconds, as in the electroencephalographic record of a 15-year-old male patient presenting progressive cognitive deterioration and myoclonus showed in the Figure.

Although SSPE is considered a vanishing disease ${ }^{2}$, global eradication may be hard to achieve, considering that outbreaks of measles occur worldwide on a regular basis and remain a public health problem in many countries ${ }^{3-5}$.

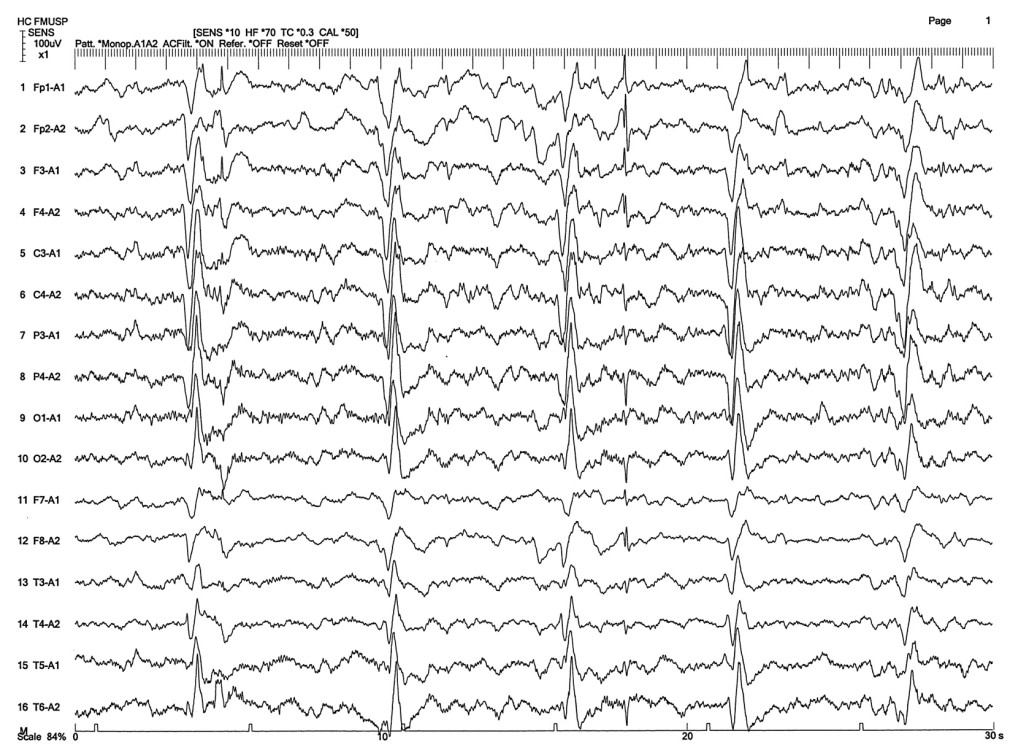

Figure. Thirty-second epoch of an electroencephalographic record, performed in April 2011, in a case of subacute sclerosing panencephalitis, disclosing periodic long-interval diffuse discharges, occurring every seven seconds. Parameters are as follows: sensitivity $10 \mu \mathrm{V} / \mathrm{mm}$, time constant $0.3 \mathrm{~s}$ and high-frequency filter $70 \mathrm{~Hz}$.

\section{References}

1. Dunand AC,Jallon P. Les activités paroxystiques pseudo-périodiques en électroencéphalographie. Neurophysiol Clin 2002;32:2-37.

2. Gadoth N. Subacute sclerosing panencephalitis (SSPE) the story of a vanishing disease. Brain Dev 2012;34:705-711.

3. Kupferschmidt K. Europe's embarrassing problem. Science 2012:336:406-407.
4. Mulholland EK, Griffiths UK, Biellik R. Measles in the 21st century. N Engl J Med 2012;366:1755-1757.

5. Oliveira MI, Figueiredo CA, Afonso AM, et al. Ressurgence of measles vírus in São Paulo, Brazil. Rev Inst Med Trop Sao Paulo 2012;54:113-114.

${ }^{1} \mathrm{MD}$, Department of Neurology, Universidade de São Paulo (USP), São Paulo SP, Brazil;

${ }^{2}$ PhD, Department of Neurology, USP, São Paulo SP, Brazil.

Correspondence: Francisco Pereira da Silva-Júnior; Rua Doutor Melo Alves 55 / apto. 123; 01417-010 São Paulo SP - Brasil; E-mail:franciscops@hotmail.com Conflict of interest: There is no conflict of interest to declare.

Received 07 July 2012; Received in final form 22 November 2012; Accepted 29 November 2012. 